\title{
Development of a mini tractor drawn semiautomatic two row planter cum fertilizer applicator
}

\author{
Kapil Mandloi, R. Swarnkar, Yagnik C. Yoganandi, Hardik K. Raulji and K. L. Dabhi
}

Received : $30.05 .2017 ;$ Revised : $02.02 .2018 ;$ Accepted : 11.02 .2018

See end of the Paper for authors' affiliation

Correspondence to :

\section{Kapil Mandloi}

Department of Farm Machinery and Power

Engineering, College of Agricultural Engineering and

Technology (A.A.U.), Godhra (Gujarat) India
- ABSTRACT : The potato planter is a very important machine, there is not much research available to show its effect on growth of plant or yield. But it proves its importance in time bounded operation, conservation and better utilization of energy, increased productivity of labour and overall precision in farm operations. Now days the majority of farmers are small and marginal and they cannot afford big sized tractors, so some cheaper mechanization for various farm operations is needed. Planting or sowing operation needs more accuracy than other farm operations, as costly seeds and fertilizer can be saved by using appropriate planting machine for respective crops. In fact, mini tractors are current demand for farmers as it can perform all the operations like big tractors with appropriate matching implement. By considering the above facts and to introduce a low cost appropriate technology for semiautomatic potato planter that can be operated by mini tractor, a mini tractor operated semiautomatic potato planter has been developed. The potato planter places potato tubers and fertilizer simultaneously at appropriate depth and the cost of operation of the planter is $1562 \mathrm{Rs}$./ha which is almost half ( $3285 \mathrm{Rs} . / \mathrm{ha}$ ) compared to medium sized tractor operated planter. So, the mini tractor drawn semi automatic planter is recommended for the farmers of planting of potato.

- KEY WORDS : Mini tractor drawn semiautomatic, Two row planter cum fertilizer applicator

- HOW TO CITE THIS PAPER : Mandloi, Kapil, Swarnkar, R., Yoganandi, Yagnik C., Raulji, Hardik K. and Dabhi, K.L. (2018). Development of a mini tractor drawn semiautomatic two row planter cum fertilizer applicator. Internat. J. Agric. Engg., 11(1) : 13-22, DOI: 10.15740/HAS/IJAE/ 11.1/13-22. 